\title{
Synaptic Physiology of Horizontal Afferents to Layer I in Slices of Rat Si Neocortex
}

\author{
Lawrence J. Cauller and Barry W. Connors \\ Department of Neuroscience, Division of Biology and Medicine, Brown University, Providence, RI 02912
}

Layer $I$ is a dense synaptic zone ubiquitous in cerebral cortex. Here we describe a novel in vitro preparation of rat somatosensory (SI) neocortical slices that isolates the fibers that extend horizontally through layer $\mathrm{I}$, and allows intracellular and extracellular analysis of synaptic input to dendrites in layer I. Current source-density analysis of this isolated horizontal layer I input reveals monophasic current sinks restricted to layer I and the most superficial part of layer II. The layer I synaptic response of each neuron was correlated with its morphology by filling penetrated cells with biocytin. All filled cells that responded to horizontal layer I inputs were pyramidal neurons in layers II, III, or V with distal apical dendrites in layer $\mathrm{I}$. There was no evidence of antidromic activation from isolated layer I stimulation, and HRP injected into layer I was not transported via the isolated layer I pathway to cortical neurons within the slice. Therefore, this preparation provides a unique way to study an extrinsic synaptic input localized to the most distal apical dendrites of many pyramidal neurons.

In contrast to the EPSP-IPSP sequence characteristically evoked by deep layer stimulation, horizontal layer I inputs evoked long-lasting EPSPs (approximately 50 msec); IPSPs were observed only rarely, in the most superficial neurons. Horizontal layer I-evoked EPSPs were blocked by the nonNMDA glutamate receptor antagonist 6-cyano-7-nitroquinoxaline-2,3-dione. Consistent with the very distal site of layer I inputs to layer $V$ pyramidal neurons, the amplitudes of initial EPSPs were insensitive to manipulations of the somatic membrane potential. However, these distal EPSPs were greatly attenuated when combined with IPSPs evoked by deep layer stimulation, indicating that the proximal inputs may modulate distal EPSPs with shunting inhibition. In many layer $\mathbf{V}$ neurons, the initial EPSP evoked by horizontal layer I stimulation was followed by a variable late depolarization that was blocked by the NMDA receptor antagonist 2-amino5-phosphonovaleric acid. Since these late depolarizations were enhanced by somatic depolarization and abolished by hyperpolarization, they appeared to be generated postsynaptically at a site more proximal than the initial EPSP that was insensitive to these manipulations. Synaptic inputs to

\footnotetext{
Received Jan. 4, 1993; revised July 26, 1993; accepted July 29, 1993.

We thank David Berson for guidance with anatomical techniques and Isabelle Bulthoff for help with neuronal reconstructions. This work was supported by an NIH postdoctoral fellowship (NS08376) to L.J.C., and by an NIH grant (NS25983) and an ONR grant (N00014-90-J-1701) to B.W.C.

Correspondence should be addressed to Larry Cauller, Cognition and Neuroscience, GR 41, P.O. Box 830688, University of Texas at Dallas, Richardson, TX 75083-0688.

Copyright (c) 1994 Society for Neuroscience $0270-6474 / 94 / 140751-12 \$ 05.00 / 0$
}

the distal tufts of pyramidal neurons may trigger active currents along the apical dendrites that amplify the EPSP on its way to the soma.

[Key words: neocortex, layer l, barrelfield, somatosensory cortex, corticocortical connections, feedback, biocytin, current source-density]

Layer I, the most superficial layer of neocortex, is the site of synaptic terminations from corticocortical projections (WongRiley, 1978; Rockland and Pandya, 1979). As a general rule, each of the cortical sensory systems sends "forward" projections from primary areas to the middle layers of higher-order cortical areas (e.g., V1 to V2), which are reciprocated by "backward" projections that terminate densely in layer I of primary areas (e.g., V2 to V1; Pandya and Yeterian, 1985; Zeki and Shipp, 1988; Felleman and Van Essen, 1991). These backward cortical projections are significant because they may support reentrant interactions between cortical areas (Edelman, 1979, 1989), they may convey limbic influences to neocortex for memory organization (Rolls, 1989; Squire and Zola-Morgan, 1991), they may serve to bind sensory properties into a unified percept (Damasio, 1989; cf. Mesulam, 1990), and they may help synchronize oscillatory activity (Sporns et al., 1989; Eckhorn et al., 1990). Only recently, physiological studies have shown that backward cortical projections can mediate visual responses in primary visual cortex (Mignard and Malpeli, 1991). Furthermore, a sensoryevoked potential in primary somatosensory cortex that predicts touch discrimination behavior in awake monkeys is generated by excitation of layer I, apparently as a result of backward activation from higher cortical processes (Cauller and Kulics, 1991). However, the potential role of the backward projections to layer I has been generally discounted except for the most superficial neurons (Hyvarinen, 1982), because of the great distance between layer I dendrites and the somata of deeper neurons.

Physiological investigations have concentrated upon the backward cortical projections in the visual system from extrastriate areas to area 17 (i.e., V2 to V1). Initial studies employed reversible lesions in $\mathrm{V} 2$ of squirrel monkeys to show that these corticocortical projections modulated the overall responsiveness of V1 neurons to visual stimuli without changing their directional or orientation preferences (Sandell and Schiller, 1982). Using direct stimulation of V2 and V3 in cats, Bullier et al. (1988) demonstrated that backward projections to V1 are visuotopically and functionally organized. More recently, Mignard and Malpeli (1991) have shown the projection from V2 to V1 in the cat can support the complex visual responses of upper layer neurons in the absence of direct thalamocortical inputs to V1, thereby avoiding the potential confound of intracortical antidromic stimulation. These studies suggest that backward 
Figure 1. Schematic diagram of slice preparation in which the horizontal layer I $(H L I)$ pathway is isolated by a vertical cut through deeper layers. Characteristic responses to HLI stimulation (solid traces; average $n=5$ ) are compared to responses evoked by conventional columnar stimulation of layer VI ( $L V I$; broken traces; average $n=5$ ). Extracellular responses were recorded in layers I, II, and III and intracellular responses recorded in a layer $\mathrm{V}$ cell at resting potential. Reprinted with permission from Cauller and Connors (1992).

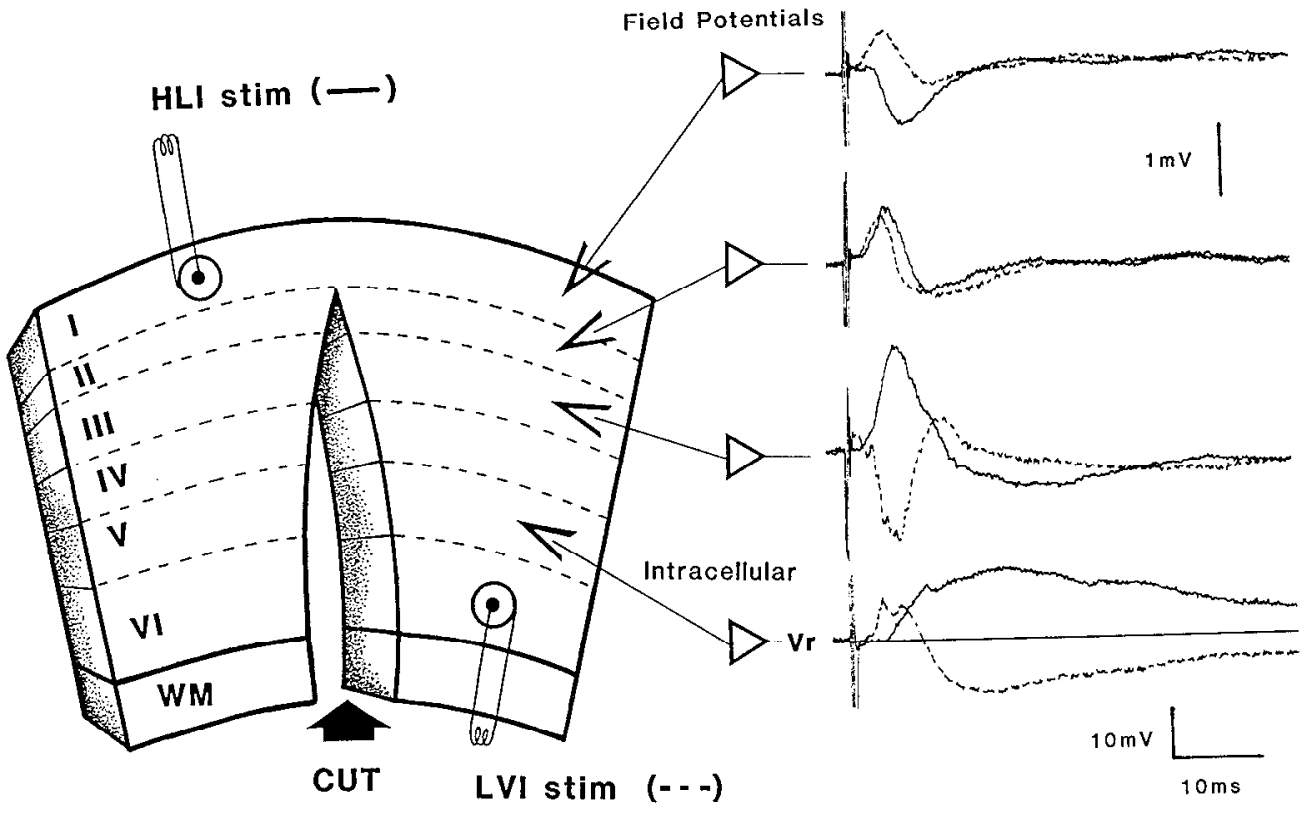

projections affect specific target cells in relatively precise ways, as opposed to a distributed modulatory influence that may be expected given the horizontal extent of backward projections to layer I (Rockland and Virga, 1989; Cauller and Connors, 1989, 1990). However, since the layer I component of the somatosensory-evoked potential is specifically abolished during slowwave sleep and anesthesia (Cauller and Kulics, 1988), those studies that employed anesthetized preparations may better represent the response mediated by the component of the backward projections that terminate in deep layers.

Layer I of neocortex is distinguished by the very low density of neurons found there, most of which are GABAergic (Gabbott and Somogyi, 1986; Winer and Larue, 1989; Anderson et al., 1992). However, layer I, referred to as the "plexiform" or "molecular" layer by Ramon y Cajal (DeFelipe and Jones, 1991), is primarily a synaptic zone filled with mostly asymmetric round, presumably excitatory synapses upon the dendritic spines of pyramidal neurons whose cell bodies lie deeper in layers II, III, and V (Jones and Powell, 1970; Adinolfi, 1972; Vaughn and Peters, 1973; Jones, 1981; Beaulieu and Colonnier, 1985). Until the system of backward cortical projections was widely recognized, excitatory inputs to layer I were believed to originate either intrinsically as the axons of local neurons (e.g. "Martinotti" cells; DeFelipe and Jones, 1988) or extrinsically in the thalamus outside the specific sensory nuclei (Killackey and Ebner, 1972; Herkenham, 1986). It is now clear that axon collaterals of local pyramidal neurons reach layer I (Martin, 1984), and that a subpopulation of thalamic neurons in the specific sensory nuclei also project to layer I (Penny et al., 1982; Rausell and Avendano, 1985). In addition, cholinergic (Bear et al., 1985; DeLima and Singer, 1986; Lysakowski et al., 1986) and monoaminergic (Emson and Lindvall, 1979) systems project heavily to layer I. The function of backward cortical projections must be considered within the context of these diverse inputs that converge in layer I upon the most distal apical dendrites of the pyramidal neurons (Vogt, 1991).

This study procceded in parallel with anatomical experiments (Cauller and Connors, 1989, 1990), which show that rat so- matosensory (SI) cortex is organized with reciprocal connections between SI and each of its target areas, including MI and SII (see also Koralek et al., 1990; Fabri and Burton, 1991). We found that backward cortical projections were a major source of extrinsic inputs to layer I of SI, and anterograde labeling of those backward projections revealed fibers that extended horizontally within layer I for at least $1 \mathrm{~mm}$ in any direction. Here we will describe the synaptic response mediated by horizontal fibers in layer I isolated by dissection of the in vitro cortical slice.

Preliminary reports of this and the anatomical study have been presented elsewhere (Cauller and Connors, 1989, 1990).

\section{Materials and Methods}

Adult (100-450 gm) male and female, albino and Long-Evans rats (Charles River) were subjects for all experiments. No systematic experimental differences were observed within this population. Coronal in vitro cortical slices were prepared with a vibratome in the usual way (Connors et al., 1982) and maintained in a Haas-type interface chamber (Medical Systems) with perfusion $(0.5-1 \mathrm{ml} / \mathrm{min})$ of artificial cerebrospinal fluid (in mM: $\mathrm{NaCl}, 126 ; \mathrm{KCl}, 3 ; \mathrm{MgSO}_{4}, 1-2 ; \mathrm{CaCl}_{2}, 2 ; \mathrm{NaHCO}_{3}$, 26; $\mathrm{NaH}_{2} \mathrm{PO}_{4}, 1.25$; dextrose, 10; saturated with $95 \% \mathrm{O}_{2}, 5 \% \mathrm{CO}_{2}, \mathrm{pH}$ $7.4,31-34^{\circ} \mathrm{C}$ ). Slices were prepared from the middle third of the cerebral hemisphere from the rostral septum to the caudal striatum. Care was taken to section the slice perpendicular with respect to the midsagittal and dorsal planes to maintain continuity of the apical dendrites of deep pyramidal neurons. To isolate the horizontal layer I pathway, all other horizontal fibers below layer I were dissected with a cut perpendicular to the pial surface, extending from the visible border between layers I and II ( $0.1-0.2 \mathrm{~mm}$ below the pia) through subcortical white matter (Fig. 1).

Slices were stimulated monophasically with bipolar electrodes made from twisted pairs of thin ( 25 or $50 \mu \mathrm{m}$ diameter) insulated stainless steel wires (California Fine Wire). Horizontal layer I fibers were stimulated on one side at least $0.3 \mathrm{~mm}$ from the cut, and responses wcrc recorded at least $0.2 \mathrm{~mm}$ from the cut on the other side. Fibers ascending through layer VI were stimulated at a point no more than $0.2 \mathrm{~mm}$ above the white matter. Evoked field potentials were recorded with low-impedance $(<5 \mathrm{M} \Omega)$ micropipettes filled with $0.5 \mathrm{M} \mathrm{NaCl}$, amplified (1000×; $1 \mathrm{~Hz}$ to $1 \mathrm{kHz}$ ) and stored on FM tape for off-line analysis.

For current source-density (CSD) analysis, evoked field potentials were collected sequentially at $50 \mu \mathrm{m}$ intervals along a straight line per- 
Table 1. Sampled neurons (number responsive to layer I stimulation in parentheses)

\begin{tabular}{lccc} 
& & \multicolumn{2}{c}{ Biocytin-filled } \\
\cline { 3 - 4 } Layer & Total & Pyramidal & Nonpyramidal \\
\hline II & $2(2)$ & $1(1)$ & \\
III & $11(5)$ & $5(5)$ & \\
IV & $3(0)$ & & $2(0)$ Spiny stellates \\
V & $31(14)$ & $11(7)$ & $2(0)$ Smooth stellates \\
$\quad$ Regular spiking & $18(6)$ & $3(2)$ & \\
Intrinsic bursting & $11(8)$ & $8(5)$ & \\
VI & $6(0)$ & $4(0)$ & \\
Total & $53(21)$ & $21(13)$ & \\
\end{tabular}

pendicular to the pial surface starting at least $100 \mu \mathrm{m}$ above the surface (i.e., in the bath) and extending across all cortical layers to white matter. To construct transcortical profiles of the evoked activity, five responses to equal stimuli were collected at each site. Response stability was checked by comparing the response near the maximal site before and after the profile was completed. Digitally sampled responses (12 bit; $10 \mathrm{k} \mathrm{samples} / \mathrm{sec}$ ) from each site were averaged and profiles were processed for CSD by the second nearest neighbor method of second finite differences (Nicholson, 1979). Approximate laminar boundaries were identified by direct visual inspection of the slice during data collection as in Agmon and Connors (1991).
Sharp micropipettes (Brown Flaming puller, 120-160 M $\Omega$ ) filled with $1 \mathrm{M} \mathrm{K}$-acetate ( $\mathrm{pH} 7.4$ adjusted with $\mathrm{KOH}$ or acetic acid) were used for intracellular penetrations. Intracellular recording and current injection were controlled with a current-clamp electrometer (Axoclamp-2A, Axon Instruments). To identify the morphology of penetrated cells, biocytin (3-5\%; Molecular Probes) was added to the filling solution and injected by electrophoresis $(0.5 \mathrm{nA}, 50 \%$ duty cycle, $1 \mathrm{~Hz}$ for $10 \mathrm{~min})$. Slices were fixed by submersion overnight in $4 \%$ paraformaldehyde phosphate buffer (PF; $0.1 \mathrm{M}, \mathrm{pH} 7.4$ ), sunk in $30 \%$ sucrose phosphate buffer, and frozen-sectioned $60 \mu \mathrm{m}$ thick through the plane of the slice (i.e., six or seven sections/slice). Following $\mathrm{H}_{2} \mathrm{O}_{2}(0.5 \%)$ and Triton X-100 (1\%) pretreatment, sections were processed for biocytin by overnight incubation in avidin-HRP (ABC standard, Vector Labs), and then the HRP was reacted with cobalt-intensified diaminobenzidine (protocol available upon request). The numbers of neurons sampled from each layer and of each morphology identified are presented in Table 1. These numbers reflect our particular interest in layer $\mathrm{V}$ neurons. The penetrations in superficial layers were often attempted following failure to find responsive cells in deeper layers. Intracellular penetrations were only attempted in slices that yielded typical extracellular responses to horizontal layer I stimulation (absolute amplitude in layer I $>0.2 \mathrm{mV}$ ).

Neurons of layer $\mathrm{V}$ were classified as regular spiking or intrinsically bursting on the basis of their firing behavior during intracellular current injection. Regular-spiking neurons respond to depolarization with repetitive single action potentials in an adapting pattern. In contrast, intrinsically bursting neurons respond with brief, high-frequency bursts of two or morc action potentials, superimposed upon a slow depolarizing potential, which may repeat or switch to single-spiking mode during sustained current injection. As previously described (Chagnac-Amitai et al., 1990; Connors and Gutnick, 1990; Larkman and Mason, 1990), these intrinsic physiological properties have been correlated with distinct morphological and connectional properties (see Discussion).

\section{Horizontal Layer I Stimulation} Field Potentials

\section{Current-Source Density}

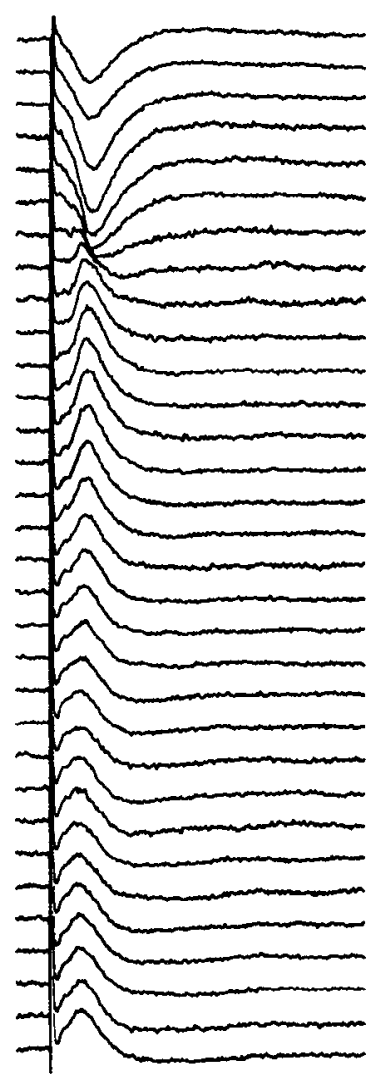

\section{Columnar Layer VI Stimulation} Field Potentials

\section{Current-Source Density}

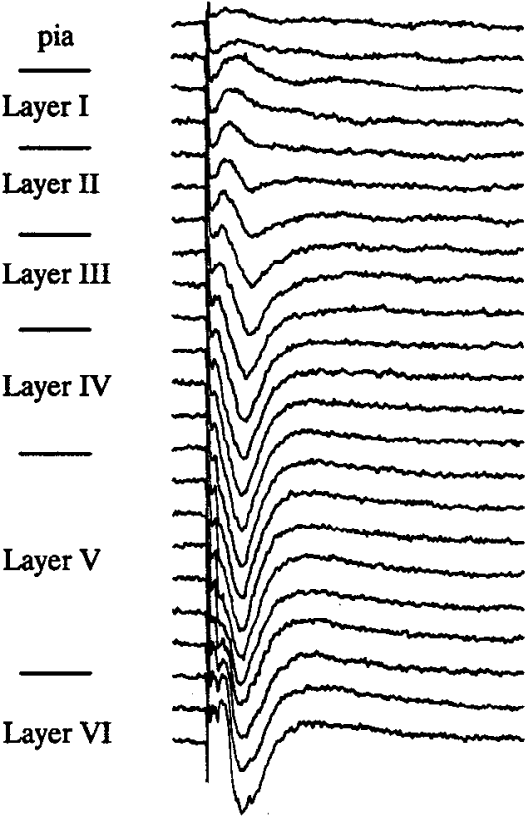

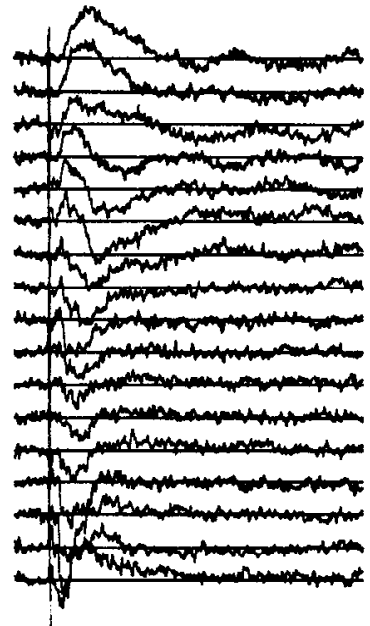

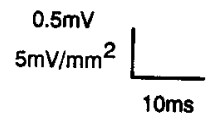

Figure 2. Laminar profiles and CSD analysis of horizontal layer I-evoked responses compared to responses evoked by conventional stimulation of layer VI. Responses were collected at $50 \mu \mathrm{m}$ intervals from just above the pial surface of the slice, in the bath, across all cortical layers to subcortical white matter. Layer I-evoked EPSPs were recorded intracellularly from layer V cells in this slice. 

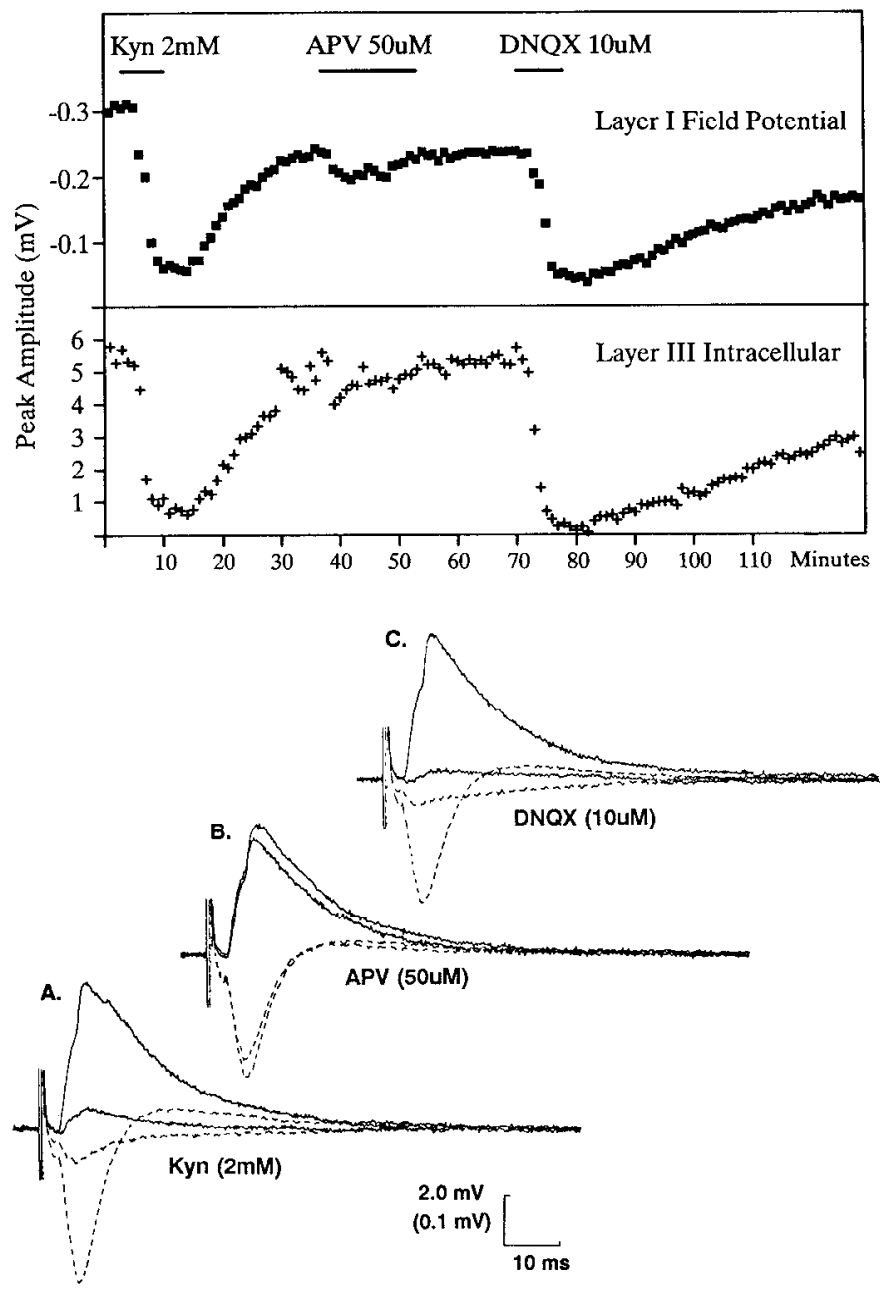

Figure 3. Layer I-evoked responses were blocked by glutamate receptor antagonists kynurenic acid $(K y n ; 2 \mathrm{mM})$ and DNQX $(10 \mu \mathrm{M})$ but not APV $(50 \mu \mathrm{M})$. Extracellular field potentials recorded in layer I and intracellular EPSPs recorded in a layer III cell were collected every 20 sec. The average $(n=3)$ peak amplitude is plotted over the course of 130 min during application of blockers to the bath perfusate indicated by horizontal bars. $A$, Average responses $(n=10)$ collected just before and at the end of 6 min application of kynurenic acid. $B$, Averages just before compared to the end of $15 \mathrm{~min}$ APV. $C$, Averages just before compared to the end of 7 min DNQX.

To trace the isolated horizontal layer I fibers in the cortical slice, HRP (Sigma type VI; $30 \%$ in distilled $\mathrm{H}_{2} \mathrm{O}$ ) was passively injected $(1-5 \mu \mathrm{m}$ tip, $0.2 \mathrm{~mm}$ penetration, $10-15 \mathrm{~min})$ into layer I $(0.1 \mathrm{~mm}$ below pia) at least $0.3 \mathrm{~mm}$ horizontally from the vertical cut. To avoid blood artifact, under general anesthesia rats were perfused transcardially with oxygenated artificial cerebrospinal fluid before the slices were prepared. Following transport times from 8-16 hr, slices were fixed by submersion in $P F$ for $5 \mathrm{~min}$, and then sectioned as described above and reacted according to the molybdate modified (Olucha et al., 1985) tetramethylbenzidine reaction (Mesulam, 1978).

\section{Results}

Stimulation of the horizontal layer I pathway, isolated by cutting all other horizontal connections in the in vitro slice, evoked a simple negative field potential that was maximal in layer I and reversed in layer II to become a positivity (Figs. 1, 2). CSD analysis confirmed that the site of excitatory synaptic activation evoked by horizontal layer I stimulation was restricted to layers I and II. Superficial current sinks were associated with smaller current sources immediately below, and no current dipoles were observed in deeper layers. The mean latency to the initial deflection of the layer I-evoked field potential, as recorded in layer I, was $3.1 \mathrm{msec}(0.3 \mathrm{msec} \mathrm{SD} ; n=38)$, and the latency to peak was 7.3 msec ( $2.1 \mathrm{msec} \mathrm{SD} ; n=38)$. In contrast, stimulation of fibers traveling through layer VI (columnar stimulation in Figs. 1 and 2) evoked negativities in middle layers associated with superficial positivities. Also in contrast to the simple horizontal layer I response, layer VI stimulation evoked complex multiphasic fields and multiple current dipoles throughout middle and deep cortical layers. Every slice that responded to layer VI stimulation also responded to horizontal layer I stimulation.

To determine the extent of collateralization of horizontal layer I fibers passing through deeper layers of the in vitro slice, HRP was injected into layer I approximately $0.3 \mathrm{~mm}$ horizontal to the vertical cut. Labeled fibers were traced across layer I to deeper layers on the other side of the cut. While numerous cells were labeled on the HRP-injected side of the cut after 8-16 hr transport time, only one cell was found on the opposite side ( $n$ $=7$ slices). Labeled fibers ascended from deep layers directly to layer I with few collaterals in deep layers. In addition, while the local collaterals of some biocytin-filled pyramidal neurons, especially in layers IV and $\mathrm{Va}$, ascended to superficial layers, no individual collateral branches extended horizontally in layer I for distances greater than $0.25 \mathrm{~mm}$. Since all of the ascending local collaterals included numerous terminal branches below layer I, they were probably not activated by horizontal layer I stimulation because the CSD analysis found no deep synaptic currents. These anatomical observations support the conclusion based upon the CSD data that the monosynaptic action of the isolated horizontal layer I pathway stimulated at least $0.3 \mathrm{~mm}$ from the cut is concentrated at the terminal zone in layer I, with very little direct activation of deeper layers.

All horizontal layer I-evoked field potentials and intracellular responses were reversibly blocked by the nonspecific glutamate antagonist kynurenic acid ( $2 \mathrm{~mm} ; n=5$ ) or the more specific non-NMDA glutamate receptor antagonists 6-cyano-7-nitroquinoxaline-2,3-dione (CNQX) or 6,7-dinitroquinoxaline-2,3dione (DNQX; 5-10 $\mu \mathrm{M} ; n=3$; Fig. 3). The NMDA glutamate receptor antagonist 2-amino-5-phosphonovaleric acid (APV; 50 $100 \mu \mathrm{M} ; n=3$ ) did not significantly affect the extracellular field potentials or the initial intracellular responses to horizontal layer I stimulation, but did block late depolarizations $(n=2)$ as described below.

A total of 53 neurons were penetrated intracellularly (resting potentials, -68 to $-81 \mathrm{mV}$; input impedances, 13-38 $\mathrm{M} \Omega$; action potentials overshoot above $0 \mathrm{mV}$ ). Only neurons impaled in layers II, III, and V responded to horizontal layer I stimulation (see Table 1). All biocytin-filled neurons that responded to horizontal layer I stimulation were pyramidal neurons with distal apical dendrites in layer I (Figs. 4, 5). All neurons penetrated in layer VI and in layer IV, including two filled spiny stellate cells, did not respond to horizontal layer I stimulation. Consistent with the general trend in other cortical areas (Jones, 1981), the superficial dendrites of these filled cells in layers IV and VI did not extend into layer I. In addition, two fast-spiking, smooth stellate cells penetrated in layer $\mathrm{Vb}$ did not respond to layer I inputs and did not have layer I dendrites. However, some filled pyramidal neurons in layer $V$ with extensive tufts in layer I also did not respond to horizontal layer I stimulation $(n=4$ of 11) despite a significant extracellular response in overlying layer I.

All filled pyramidal cells in layer $\mathrm{V}$ of SI, including both 


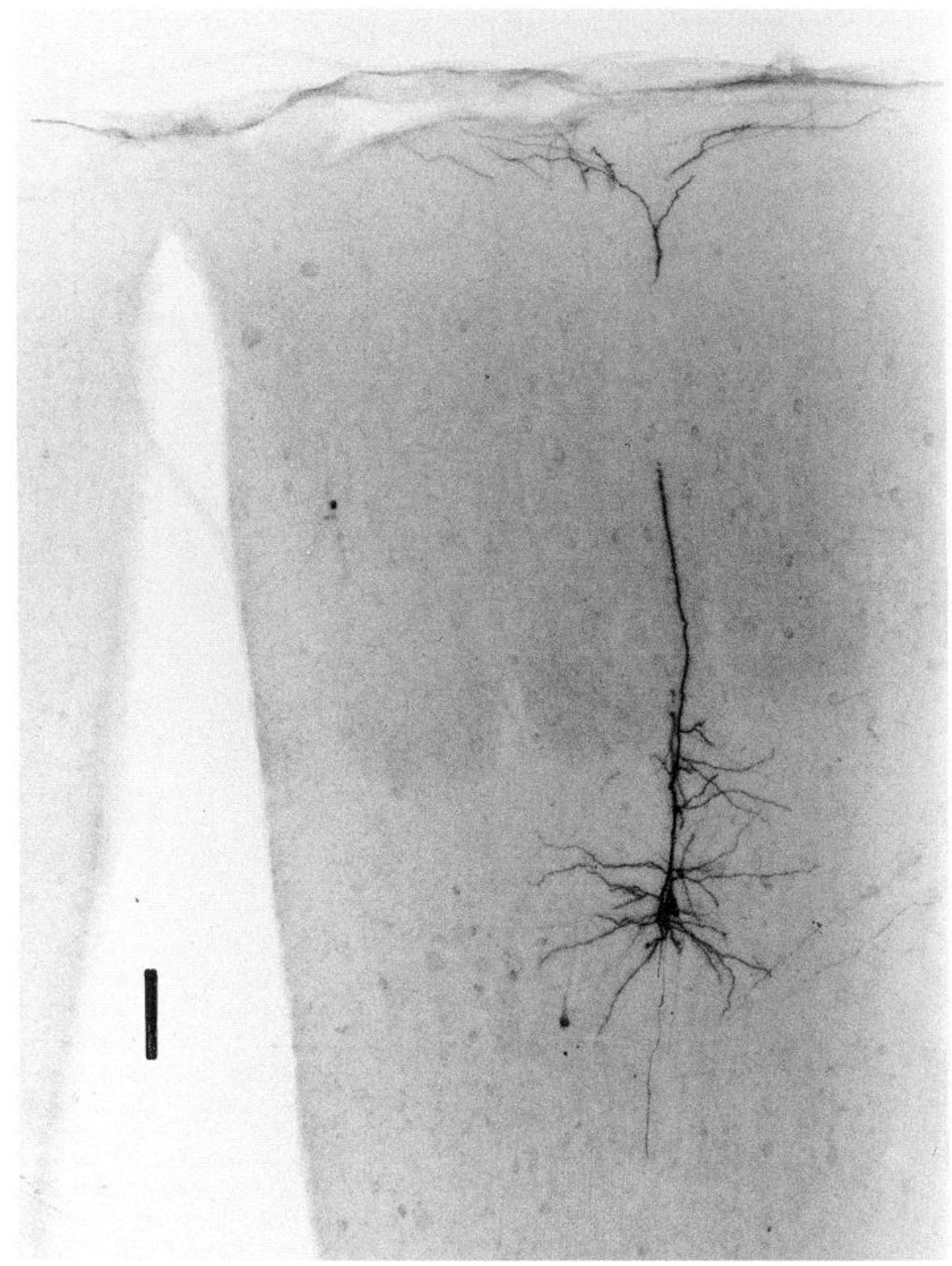

Figure 4. Photomicrograph of a biocytin-filled pyramidal neuron in layer $\mathrm{Vb}$ in a section from a slice prepared for horizontal layer I stimulation. This intrinsically bursting cell responded to horizontal layer I stimulation. A lightly filled dye-coupled cell lying very close to the primary cell body was filled by this same penetration, making the cell body appear larger than it actually was. The missing portion of the apical trunk was found in the adjacent section. Barrels are evident in layer IV. Scale bar, $0.1 \mathrm{~mm}$. regular-spiking and intrinsically bursting neurons, had apical dendrites that extended to and branched within layer I. Occasionally the distal apical dendrites of filled layer $\mathrm{V}$ cells $(n=3)$ ended at the sectioned surface before reaching layer I, indicating the slicing angle was not properly aligned with the apical axis. Such cut cells were not responsive to horizontal layer I stimulation (intrinsically bursting, $n=1$; regular-spiking, $n=2$; these cells were not included in the horizontal layer I response proportions reported in Table 1). Intrinsically bursting pyramidal neurons of layer $\mathrm{Vb}$ had especially profuse distal apical dendritic tufts in layer I with characteristic horizontal branches extending as far as $0.25 \mathrm{~mm}$ within layer I (Fig. 4), and these cells typically responded vigorously to horizontal layer I inputs.

Consistent with previous studies (Connors et al., 1982, 1988), the intracellular response of pyramidal neurons to stimulation of layer VI consisted of a brief EPSP immediately truncated by persistent IPSPs that lasted as long as $100 \mathrm{msec}$. In contrast, the intracellular response to horizontal layer I stimulation typically consisted of a simple, monophasic EPSP lasting at least $50 \mathrm{msec}$. With increasing stimulus intensity, the intracellular EPSP evoked by horizontal layer I stimulation increased monotonically with multiple action potentials evoked in some cells by strong stimuli. It was possible to evoke action potentials with strong horizontal layer I stimulation in nearly every cell that responded except for two regular-spiking neurons of layer $\mathrm{V}$. The latency of intracellular responses to horizontal layer I stimulation was significantly greater than the latency of responses to layer VI stimulation (see Figs. 1, 6, 7; initial latency to layer VI stimulation $=3.9 \mathrm{msec}, 1.3 \mathrm{msec} \mathrm{SD}, n=5$; latency to horizontal layer I stimulation $=6.4 \mathrm{msec}, 2.3 \mathrm{msec} \mathrm{SD}, n=14$; $p<0.01$; latency to peak EPSP following layer VI stimulation $=8.4 \mathrm{msec}, 2.5 \mathrm{msec} \mathrm{SD}, n=5$; latency to peak EPSP following horizontal layer I stimulation $=15.5 \mathrm{msec}, 4.8 \mathrm{msec} \mathrm{SD}, n=$ $14 ; p<0.01)$. 


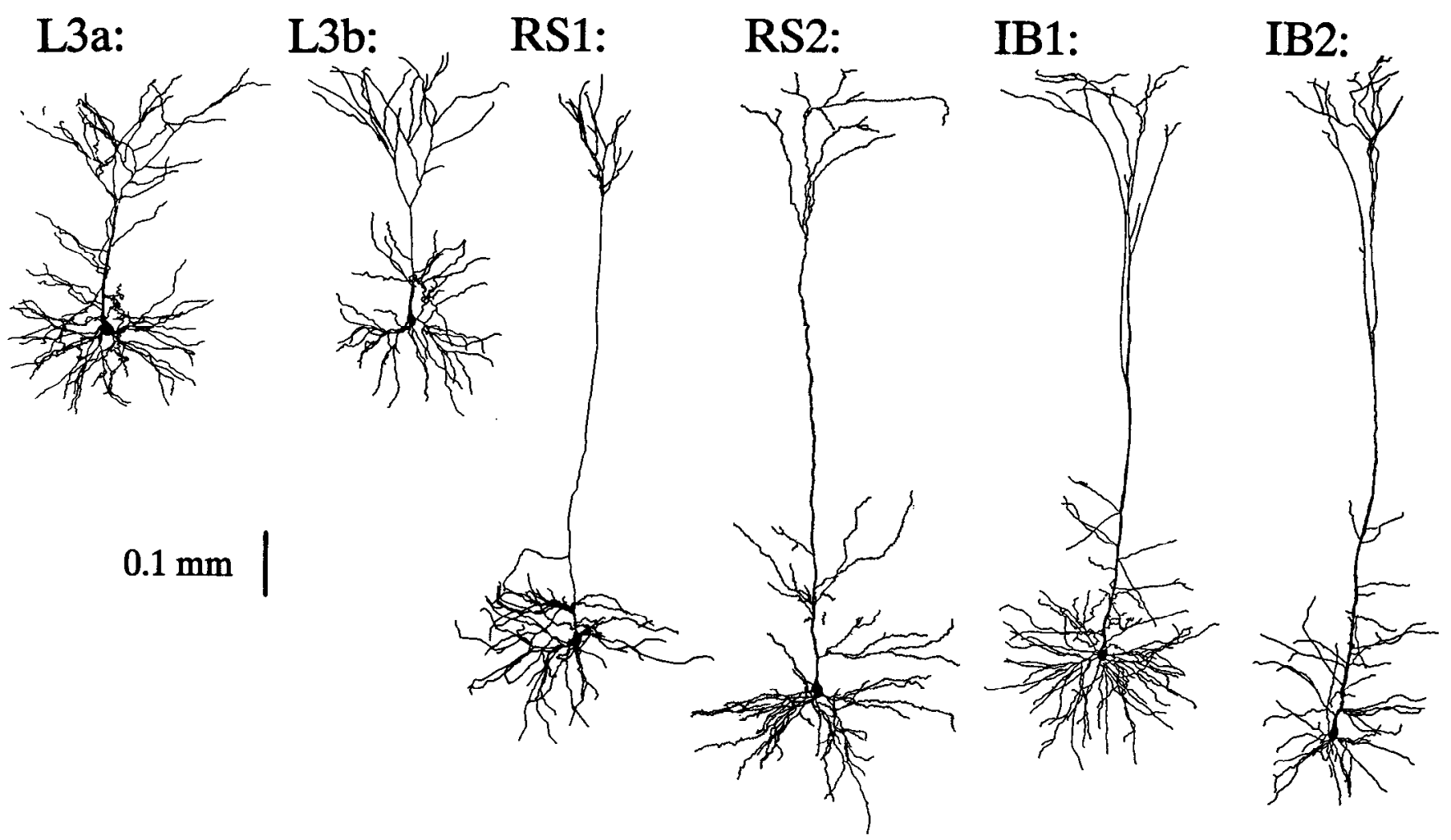

Figure 5. Camera lucida tracings of biocytin-filled pyramidal neurons whose response to horizontal layer I stimulation is shown in the following figures. Layer III cells ( $L 3 a$ and $L 3 b$ ) are compared to regular-spiking ( $R S 1$ and $R S 2)$ and intrinsically bursting (IBI and IB2) cells.
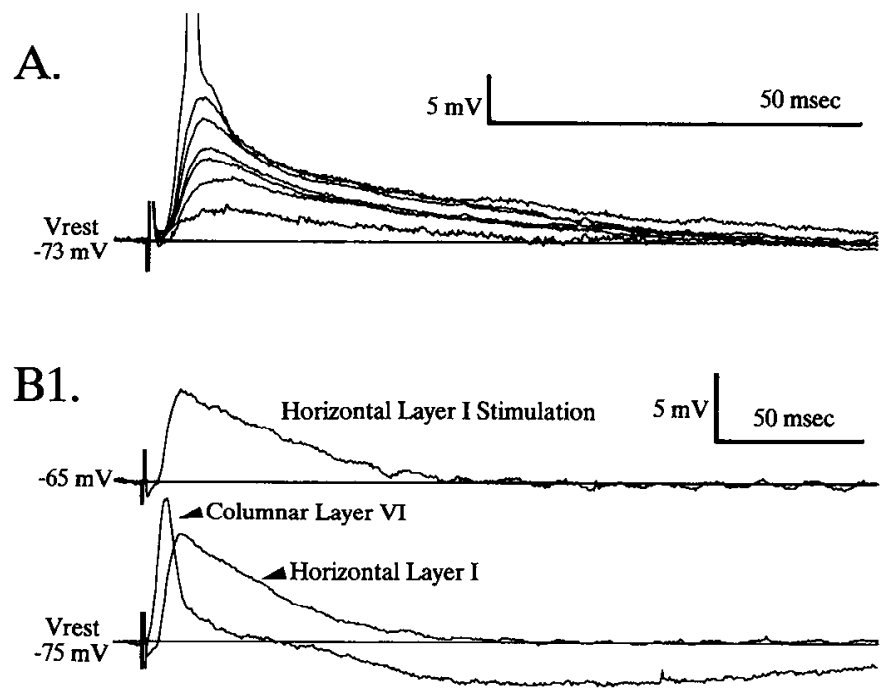

B2.

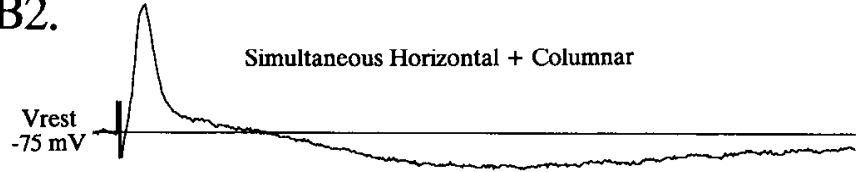

Figure 6. $A$, Characteristic EPSPs recorded in a layer III pyramidal neuron (L3a of Fig. 5) in response to a series of stimulus intensities $(0.05-0.5 \mathrm{~mA} ; 0.2 \mathrm{msec}$ pulse) applied to layer I across the cut, at a distance of $0.5 \mathrm{~mm}$ horizontally. Action potentials in this and all remaining figures were truncated graphically. $B 1$, The intracellular response of a layer III pyramidal neuron (L3b of Fig. 5) to horizontal layer I stimulation $(0.3 \mathrm{~mA})$ is compared to the response evoked by stimulation of layer VI $(0.05 \mathrm{~mA})$. In addition the layer I-evoked re-
The peak amplitude of the initial EPSP evoked by horizontal layer I stimulation was not significantly affected when the membrane potential was manipulated by somatic current injection (Figs. 6-12). This consistent observation indicates that the synapses responsible for the EPSP evoked by horizontal layer I stimulation were very electrotonically distant from the soma. In contrast, IPSPs evoked by layer VI stimulation appeared to involve proximal synapses because the reversal potentials near rest could be identified by somatic manipulation of the membrane potential (Fig. 7). When horizontal layer I stimulation was combined with simultaneous layer VI stimulation, the EPSP responses to horizontal layer I stimulation in neurons of layer III (Fig. 6B) or layer V (Fig. 7) were greatly attenuated by these proximal IPSPs. This affect was probably postsynaptic because the extracellular response in layer I was unaffected by concurrent deep stimulation. It appears, therefore, that these distal EPSPs may be shunted by proximal IPSPs.

Unlike the response to layer VI stimulation, IPSPs were rarely evoked by horizontal layer I stimulation (see Fig. $8 ; n=2$ of 5 layer III cells; $n=0$ of 14 layer V cells). In those two layer III cells, the apparent IPSPs evoked by horizontal layer I stimulation reversed more positive to rest than IPSPs evoked by layer VI stimulation (compare Figs. 7, 8). It is unclear whether this indicates the IPSPs evoked by horizontal layer I stimulation were electrotonically distant from the soma or whether these

\section{$\longleftarrow$}

sponse recorded during depolarizing current injection shows no IPSPs. $B 2$, When layer I stimulation was simultaneous with layer VI stimulation, the layer VI-evoked IPSPs masked the horizontal layer I response. 
A Layer VI (LVI) Stimulation

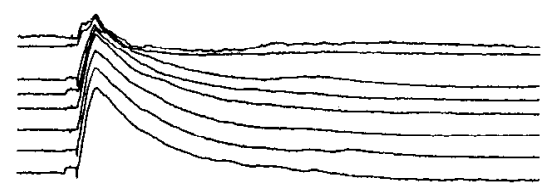

$-71 \mathrm{mV}$

[

B $\quad \mathrm{LVI}+\mathrm{HLI}$

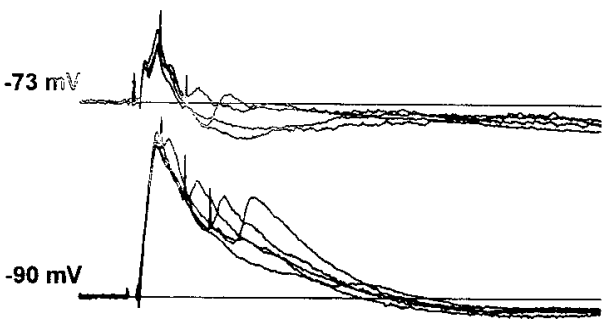

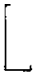

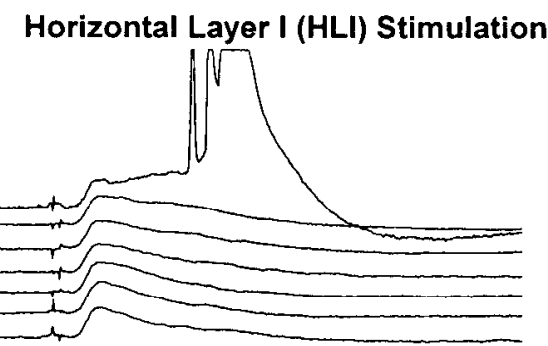

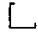

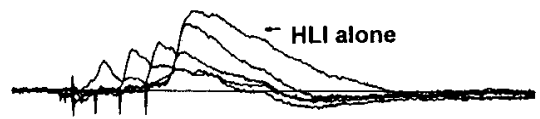

$\longleftarrow$

D Extracellular Fields in Layer I

Subtracted Responses

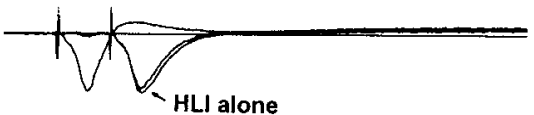

[

Figure 7. A, Responses to layer VI stimulation ( $L V I$, left $)$ or horizontal layer I stimulation $(H L I$, right $)$ were recorded in the same layer V neuron while the somatic membrane potential was manipulated by steady current injection (resting potential $=-76 \mathrm{mV}$ ). LVI stimulation evoked the characteristic EPSP-IPSP sequence, and the IPSP reversed near or slightly negative to resting potential. HLI stimulation evoked a prolonged EPSP that was evidently distant from the soma because it was not increased by hyperpolarization. When depolarized, the HLI-evoked EPSP triggered a late burst of action potentials. All traces in this figure are averages of five or more responses except for the suprathreshold HLI-evoked response. All intracellular records are from the same neuron. $B$, HLI stimulation was simultaneous with, or delayed by 5,10 , or 15 msec after, LVI stimulation during depolarizing or hyperpolarizing steady current injection. The response to LVI stimulation alone is also plotted. $C$, These waveforms equal the difference between the responses to combined stimulation (LVI+HLI) minus the responses to LVI stimulation alone under the hyperpolarized condition. The response to HLI stimulation alone at $15 \mathrm{msec}$ delay is superimposed for comparison. The HLI-evoked EPSP is strongly attenuated during the early LVI-evoked IPSP. Note that the late portions of the HLI-evoked EPSPs outlasted the early IPSP. $D$, Extracellular responses recorded in layer I were subtracted as in $C$. Unlike the intracellular EPSPs, the extracellular HLI-evoked EPSPs were not attenuated by concurrent LVI stimulation. It is unlikely, therefore, that the intracellular attenuation was due to a presynaptic effect of LVI stimulation upon the HLI inputs. Calibrations: $5 \mathrm{msec}$; intracellular $5 \mathrm{mV}$, extracellular $0.5 \mathrm{mV}$.

IPSPs were simply superimposed upon longer-lasting EPSPs. In either case, the IPSPs appeared to involve more proximal synapses because they were influenced by somatic manipulations while the EPSPs were not.

In many neurons that responded to horizontal layer I stimulation, the initial EPSP was followed by variable, multiphasic depolarizing potentials lasting up to $200 \mathrm{msec}$ (e.g., Fig. 11). Unlike the initial EPSP, these late depolarizations were sensitive to somatic current injections such that somatic hyperpolarization reduced the variability and abolished all late depolarizations observed after 50 msec (Figs. 9-11). These late depolarizations were most common among intrinsic bursting neurons of layer $\mathrm{Vb}(n=4$ of 8 ) but were also observed in a regularspiking neuron of layer III $(n=1$ of 5$)$ and layer $\mathrm{V}(n=1$ of $6)$. As shown in Figures $9 B$ and $11 B$, the late depolarizations evoked by horizontal layer I stimulation were not simply active somatic potentials triggered by the initial EPSP because intrasomatic current injection did not activate any such secondary depolarizations. These late depolarizations evoked by horizontal layer I stimulation could activate single or multiple action potentials or even multiple bursts of action potentials at any time during their long and variable duration (Figs. 9-12). The effect of the NMDA glutamate antagonist APV (50-100 M) upon the late depolarizations was studied in two layer $V$ cells. In both cases, APV reversibly blocked the late depolarizations evoked by horizontal layer I stimulation (Fig. 12).

\section{Discussion}

This study employed a modification of the cortical slice preparation designed to isolate horizontal synaptic inputs to layer I. Two findings support the conclusion that synaptic activation of this modified slice was restricted to the most superficial layers: 


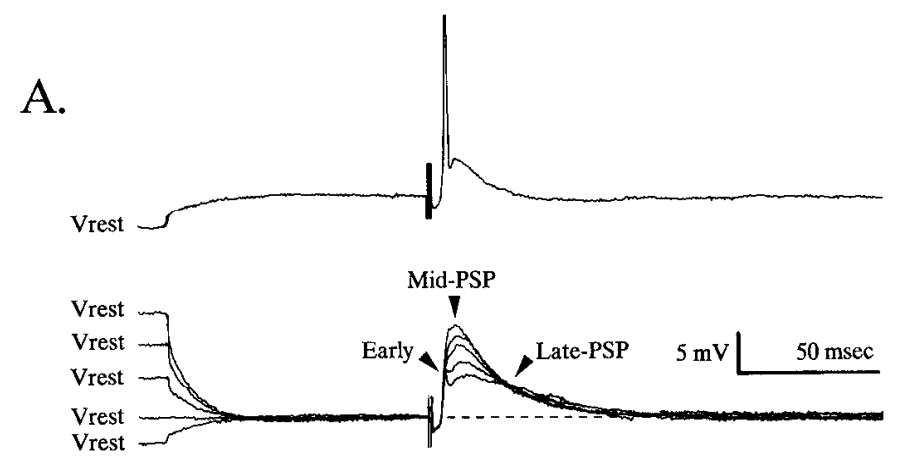

B.

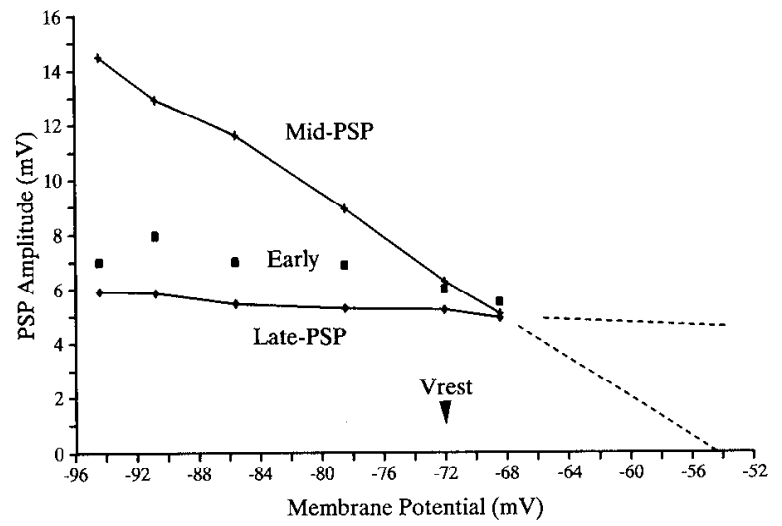

Figure 8. A, Average intracellular responses $(n=5)$ to horizontal layer I (HLI) stimulation applied during current injection were aligned at the prestimulus potential to show the change in PSP amplitude as a function of membrane potential. Data recorded in a layer III pyramidal neuron. The top trace shows that the HLI stimulation during further depolarization triggered an action potential from the rising phase of the EPSP. $B$, Amplitudes of the three major components of the HLI-evoked response indicated in $A$ are plotted as a function of prestimulus membrane potential. The mid-PSP regression projects to a null potential at approximately $-54 \mathrm{mV}$, while the early and late PSPs are nearly independent of membrane potential.

(1) CSD analysis of extracellular fields revealed current sinks restricted to layers I and II, and (2) intracellularly recorded EPSPs were very distant from the soma because they were unaffected by somatic voltage manipulations. In addition, stimulation of horizontal layer I inputs did not evoke the intracellular IPSPs that are characteristic of the response to middle layer inputs (Connors et al., 1988). The relatively short latency of the extracellular layer I response and the absence of deeper extracellular dipoles indicate horizontal layer I inputs activated the superficial dendrites monosynaptically. Similarly, since the initial intracellular EPSPs were very distant and of relatively short latency, they likewise appear to be activated monosynaptically.

This isolated horizontal layer I slice provides an in vitro preparation for the study of an afferent cortical pathway. Two other slice preparations also isolate cortical afferent pathways (thalamocortical, Agmon and Connors, 1991; callosal, Vogt and Gorman, 1982). These preparations offer an advantage over conventional stimulation of white matter or layer VI because they avoid direct stimulation of local cortical circuits and limit the extent of activation. In addition, since local cells do not appear to project horizontally within layer $I$, this preparation may avoid antidromic activation of local neurons and their collaterals.

The finding that the response to horizontal layer I inputs was
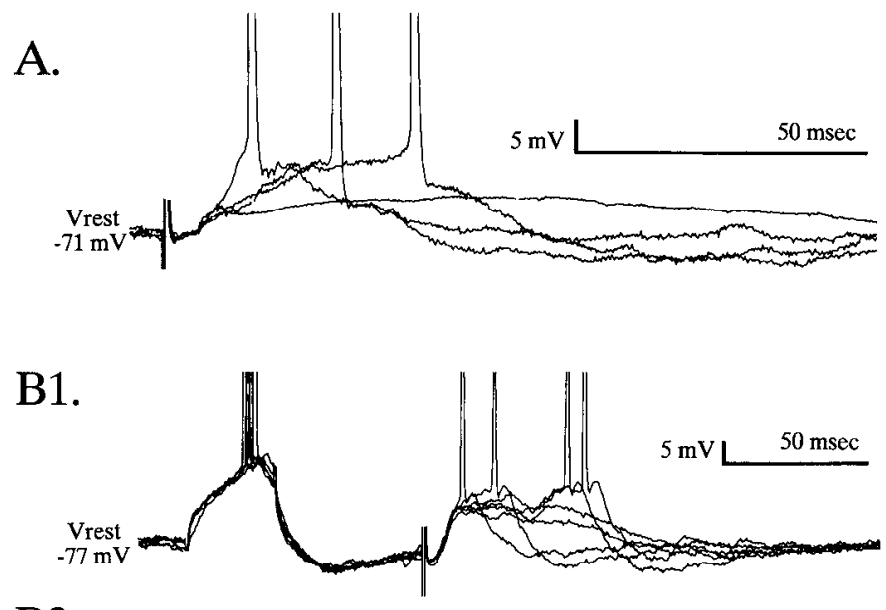

B2.

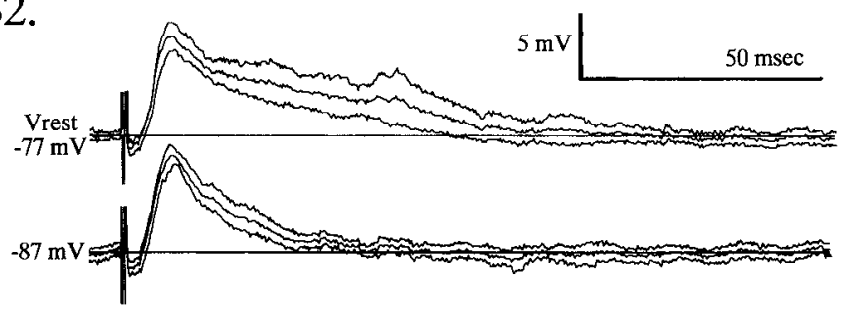

B3.

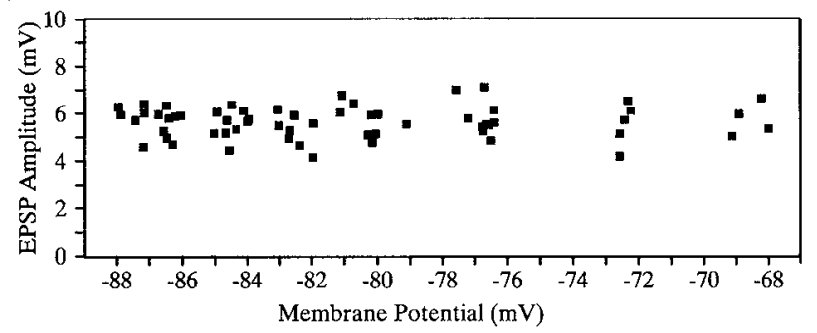

Figure 9. Intracellular layer I-evoked EPSPs recorded in two layer V regular-spiking pyramidal neurons; $A$ is from RS1 and $B$ is from RS2 of Figure 5. $A$, Responses to increasing stimulus intensities $(0.1-0.4$ $\mathrm{mA} ; 0.2 \mathrm{msec}$ pulse) evoked shorter-latency action potentials. The subthreshold response is an average $(n=10)$ while suprathreshold responses are single trial examples. $B 1$, Equal layer I stimuli $(0.35 \mathrm{~mA}$ delivered at $100 \mathrm{msec}$ ) evoked variable responses with action potentials triggered any time during the response. Five single-trial examples are shown including two subthreshold responses. The horizontal layer I stimulus was preceded by a positive current injection pulse to show the stability of the recording and the lack of long, active, somatic current-evoked events. $B 2$, The average responses $(n=5) \pm 1$ SD evoked by subthreshold layer I stimulation $(0.2 \mathrm{~mA})$ at resting potential $(-77 \mathrm{mV})$ and hyperpolarized $(-87 \mathrm{mV})$ by steady negative current injection. Note that the variable late component of the response was abolished by hyperpolarization. B3, The peak amplitude of the initial, subthreshold layer I-evoked EPSP during steady current injection was independent of somatic membrane potential.

mediated by glutaminergic receptors is consistent with the involvement of thalamocortical or reciprocal corticocortical inputs to layer I. Presently, it is not possible to distinguish the relative contribution of these two sources to the horizontal layer I-evoked response, although we have found that more cortical cells than thalamic cells are filled by retrograde transport from layer I HRP applications (Cauller and Connors, 1989, 1990). Preliminary studies using slices prepared following undercut lesions and degeneration of subcortical inputs have demonstrated that residual corticocortical inputs may support the response 


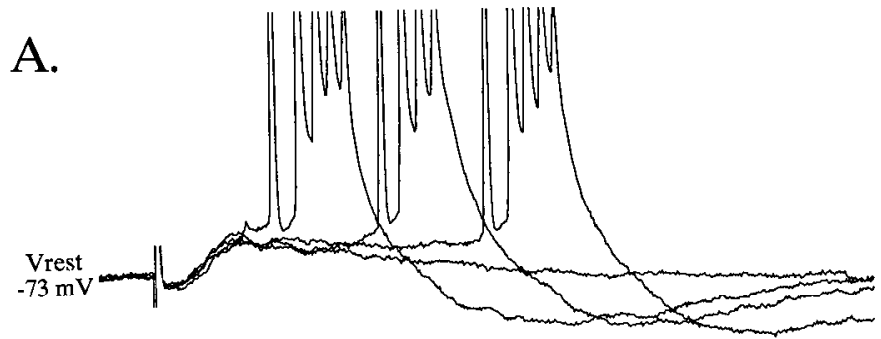

$10 \mathrm{mV}$

B.

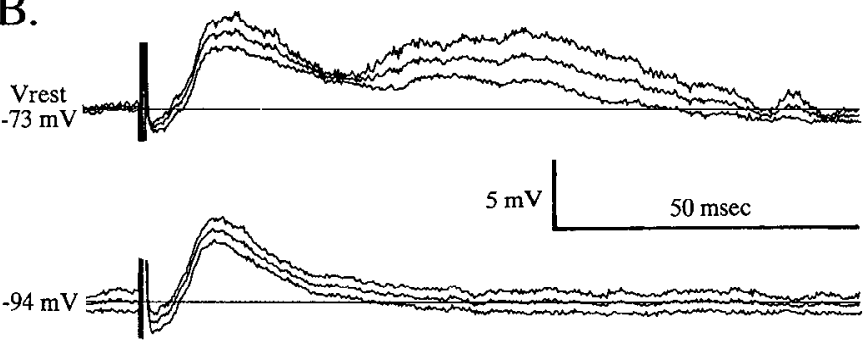

C.

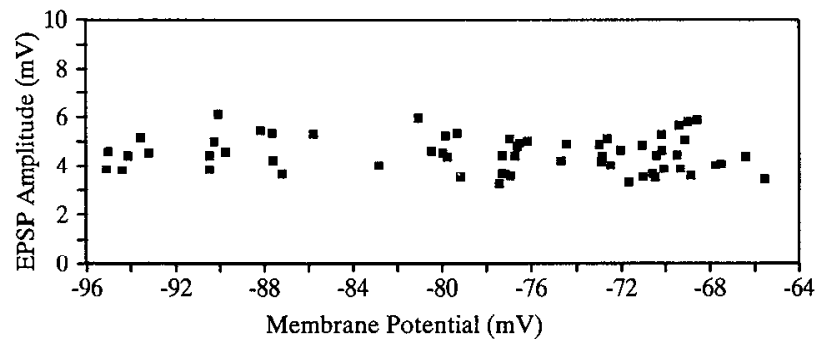

Figure 10. Intracellular layer I-evoked EPSPs recorded in an intrinsically bursting pyramidal neuron of layer V (IBI of Fig. 5). $A$, Variable suprathreshold burst responses to equal horizontal layer I (HLI) stimuli (0.45 mA; $0.2 \mathrm{msec}$ pulses). $B$, Average responses $(n=6) \pm 1 \mathrm{SD}$ evoked by equal subthreshold layer I stimuli $(0.25 \mathrm{~mA})$ at resting potential $(-73 \mathrm{mV})$ and hyperpolarized $(-94 \mathrm{mV})$ by steady negative current injection. The variable late component of the response was abolished by hyperpolarization. $C$, The peak amplitude of the initial, subthreshold HLI-evoked EPSP during steady current injection was independent of somatic membrane potential.

to horizontal layer I stimulation (L. J. Cauller, unpublished observations).

The ability to localize the site of synaptic activation to the most distal dendrites is a significant advantage of this novel slice preparation for the study of dendritic integration. The observation that the distal EPSPs were shunted by proximal IPSPs implies that the response to the backward corticocortical inputs that target layer I may be gated by the forward inputs that activate middle layer IPSPs. Similarly, extrinsic cholinergic or adrenergic inputs that modulate outward conductances along the apical trunk, between the soma and distal dendrites, should likewise selectively modulate the response to layer I inputs.

In contrast to the findings of this study, Nakajima et al. (1988) have reported that the in vitro response of cat visual cortex to horizontal layer I inputs was insensitive to the glutamate receptor blocker kynurenic acid. They stimulated very strongly horizontal fibers in layer I greater than 2-3 $\mathrm{mm}$ long and therefore may have isolated a subset of the horizontal layer I pathway

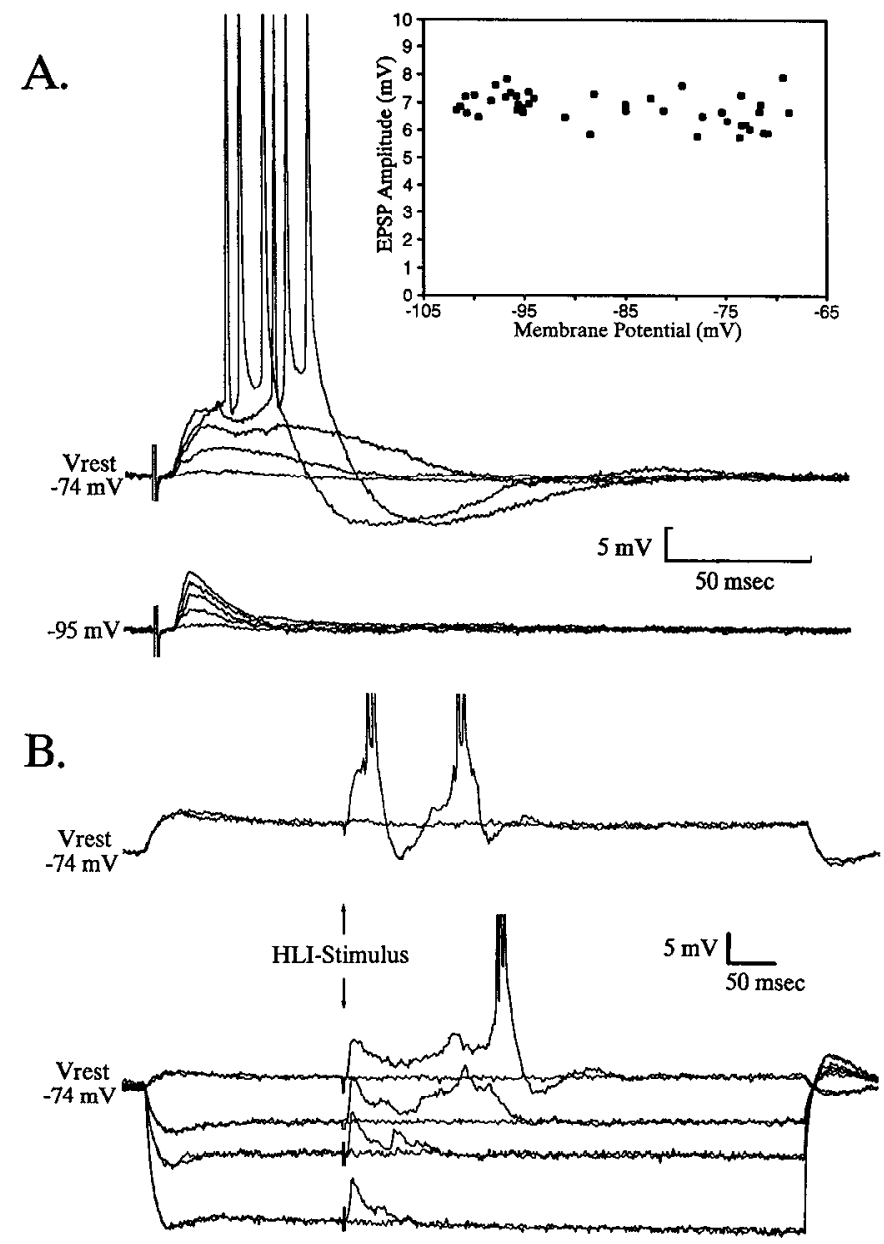

intracellular current injection

Figure 11. Intracellular layer I-evoked EPSPs recorded in an intrinsically bursting pyramidal neuron of layer V (IB2 of Fig. 5). $A$, Responses to increasing stimulus intensities $(0.1-0.5 \mathrm{~mA} ; 0.2 \mathrm{msec}$ pulse) at resting potential $(-74 \mathrm{mV})$ and hyperpolarized $(-95 \mathrm{mV})$ by steady negative current. Subthreshold responses are averages $(n>5)$ and suprathreshold responses are single trial examples. The late components of the layer Ievoked EPSPs were abolished by hyperpolarization. The inset graph shows that across a wide range of somatic membrane potentials there was no significant change in the peak amplitude of the initial layer Ievoked EPSP ( $0.4 \mathrm{~mA}$ stimulus). $B$, Single trial responses to equal layer I stimuli $(0.4 \mathrm{~mA})$ delivered during long current injections showing that the complex late response is abolished by hyperpolarization and may evoke long-latency bursts or multiple bursts. Each layer I-evoked response is superimposed upon a trial without layer I stimulation.

analyzed in this study. However, very strong stimulation did not overcome the effects of glutamate blockers in our study.

Considering the relatively long electrotonic distance from layer I synapses to the cell bodies penetrated in layers III or V, it was surprising to observe such robust responses. We have rcconstructed the morphology of these biocytin-filled pyramidal neurons in the form of compartmental cable models using the NEURON simulator (kindly provided by Hines, 1989; Cauller et al., 1991; Cauller and Connors, 1992). In this way, electrotonic properties of reconstructed pyramidal cell morphologies could be directly correlated with the physiological responses of the same neurons. This application of cable equations was used to evaluate the passive electrotonic attenuation of potentials 


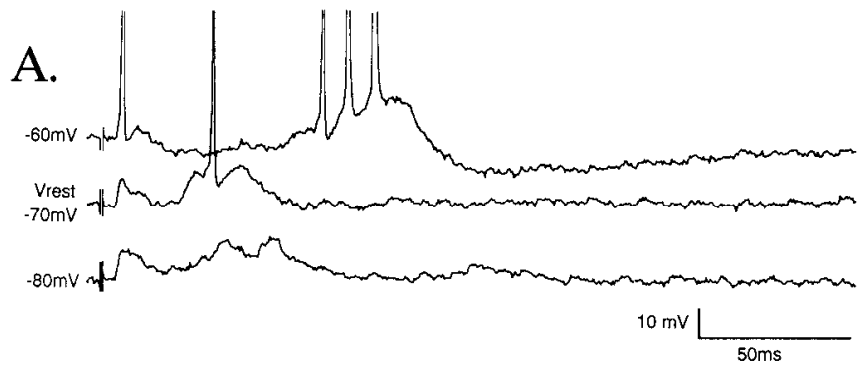

B.

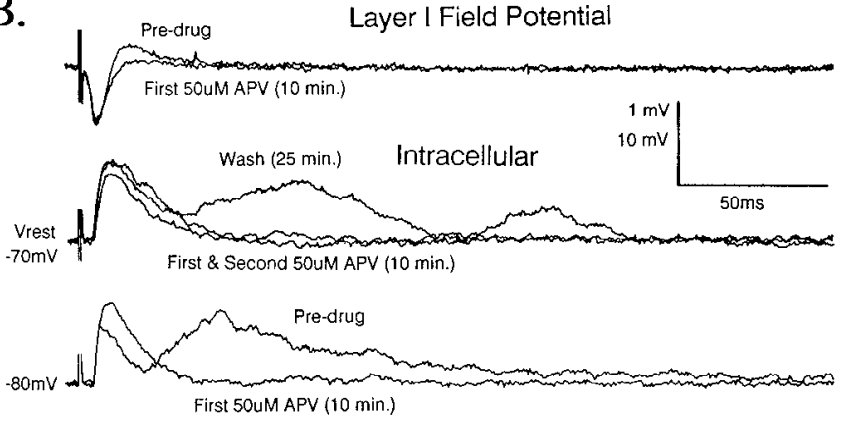

Figure 12. APV sensitivity of latc laycr I-croked intraccllular depolarizations in an intrinsically bursting cell of layer $\mathrm{V}$ (not filled with biocytin). $A$, Single trial examples of layer I-evoked responses at resting potential $(-70 \mathrm{mV})$ and during depolarizing or hyperpolarizing current injection showing complex late responses following APV washout. $B$, Layer I-evoked extracellular field potentials (top) and intracellular EPSPs (bottom two traces) during APV perfusion and washout. At the beginning of the experiment, the cell was stabilized at $-80 \mathrm{mV}$ by steady negative current (Pre-drug) and then APV was perfused $(50 \mu \mathrm{M} ; 0.6 \mathrm{ml} / \mathrm{min}$ ) for $10 \mathrm{~min}$. The average responses $(n=5)$ at the end of the APV perfusion are shown while the cell was hyperpolarized (bottom) and after current injection was turned off (middle traces). The late components of the response returned following $25 \mathrm{~min}$ washout (middle traces and $A$ ). A second perfusion of APV again abolished the late components of the responsc. APV slightly reduced the midlatency ficld potential.

between layer I and the soma. In agreement with experimental findings, the simulated passive response to layer I synaptic inputs was not significantly affected by manipulation of the somatic potential unless the axial resistivity was much lower than accepted values $(<10 \Omega \cdot \mathrm{cm}$; accepted range, $70-700 \Omega \cdot \mathrm{cm}$; Stratford et al., 1989) or the membrane resistivity was much greater than $10 \mathrm{k} \Omega \cdot \mathrm{cm}^{2}$. This value of membrane resistivity is typical of estimates based upon input resistances measured with sharp electrodes (Staley et al., 1992). In contrast, input resistances measured with whole-cell patch techniques are typically an order of magnitude greater, yielding estimates of membrane resistivity near $100 \mathrm{k} \Omega \cdot \mathrm{cm}^{2}$. The experimental finding that distal EPSPs were insensitive to somatic manipulations supports the lower estimates of membrane resistivities. Using membrane resistivities of approximately $10 \mathrm{k} \Omega \cdot \mathrm{cm}^{2}$ in these passive models matched the experimentally observed somatic input resistance. Under this condition, massive synaptic activation, resulting in maximal depolarization of the distal apical dendrites, evoked simulated somatic potentials no greater than $2 \mathrm{mV}$, much less than the responses observed experimentally. When membrane resistivity was increased to yield the observed EPSP amplitudes, the latency to peak was inordinately delayed $(>20 \mathrm{msec})$ by the increased time constant.

These observations raise the possibility that the laycr I rcsponse was amplified by active currents in the distal apical dendrites. The relatively high input impedance in the long, thin dendrites of layer I would yield relatively large local EPSPs. Therefore, fewer synaptic inputs would be required to activate high-threshold, voltage-sensitive conductances in the layer I dendrites compared to the thick proximal dendrites. Active dendritic potentials involving both calcium and sodium currents have been observed in the apical dendrites of neocortical pyramidal neurons (Huguenard et al., 1989; Pockberger, 1991; Amitai et al., 1993; Kim and Connors, 1993). However, the initial response to horizontal layer I stimulation was a graded function of the stimulus intensity, indicating that the distal response was not simply propagated to the soma by an all-ornothing dendritic spike. If the distal response was amplified by active dendritic currents, then those currents must likewise have been very distal because they were not affected by somatic manipulations.

This study poses the following paradox: very distal EPSPs could be measured in the soma, but the somatic potential did not influence the very distal dendrites. In contrast, electrotonic computations predict a greater voltage attenuation from the dendrites to the soma than from soma to dendrites (Nitzan et al., 1990) and this prediction is confirmed by our models of reconstructed cells (Cauller et al., 1991; Cauller and Connors, 1992). A possible explanation is that the very distal active currents involved high-threshold conductances (e.g., L-type calcium channels). Such currents would not be activated by attenuated somatic inputs, but they would be activated by large synaptic potentials produced in the distal dendrites where the input impedance is great.

The response to horizontal layer I stimulation always evoked a depolarizing PSP recorded from the soma at resting potential. IPSPs were only observed in upper layer pyramidal neurons where the site of synaptic inhibition appeared to be closer to the soma than layer I, because the horizontal layer I-evoked IPSP amplitude was sensitive to somatic potential while the horizontal layer l-evoked EPSP was not. Inputs to layer I may be expected to evoke inhibitory responses because the vast majority of layer I ncurons are GABAergic (Winer and Larue, 1989). It is possible that distal IPSPs were evoked by horizontal layer I stimulation and that these influenced the distal depolarizing event, but they were not identified as GABAergic due to the electrotonic distance from the soma to layer I.

While the initial EPSP evoked by horizontal layer I stimulation was insensitive to manipulations of the somatic membrane potential, secondary depolarizations were blocked by somatic hyperpolarization. These secondary potentials were found mainly in the intrinsically bursting neurons of layer V. Due to their relative sensitivity to somatic potential, it appears that the site of secondary activation was nearer the soma, presumably along the apical trunk. The sensitivity of the late activity to APV indicates NMDA receptors for glutamate were involved. This NMDA-receptor dependent late activity resembles that observed in slices from young rats prepared before neocortical inhibition is fully developed (Luhmann and Prince, 1990; sec also Sutor and Hablitz, 1989). In this study, horizontal layer I activation may have triggered late activity because it avoided the proximal inhibition that subcortical stimulation typically evokes. Since no EPSPs were found underlying the period of secondary activation during hyperpolarization, it is unlikely that polysynaptic activity was responsible for these late, voltagesensitive depolarizations. This raises the possibility that NMDA channels tonically enabled by ambient glutamate (Sah et al., 
1989) may behave like a voltage-sensitive conductance along the apical trunk.

Only pyramidal neurons with layer I dendrites responded to horizontal layer I stimulation. This implies that a subset of cortical neurons may be specialized to engage the horizontal laycr I inputs sclcctively. In particular, the apical dendrites of cells in layers IV and VI do not reach layer I, and these cells are typically the target of the specific thalamocortical inputs to middle layers. In contrast, the intrinsically bursting neurons that were strongly activated by horizontal layer I inputs characteristically have profuse layer I dendrites (Chagnac-Amitai et al., 1990; Larkman and Mason, 1990) but are not sensitive to direct thalamocortical inputs (Agmon and Connors, 1992). Thus, cortical cells may be divided with respect to their sensitivity to specific thalamocortical versus horizontal layer I inputs, and this division appears to be correlated morphologically with the extent of distal apical dendrites in layer I.

In addition to the morphological differences between cells in different cortical layers, several studies have found that the pyramidal neurons within layer $V$ may be differentiated with respect to the extent of their apical dendrites in layer I; this morphological characteristic is correlated with distinct functional and connectional properties. Among layer $\mathrm{V}$ neurons that project to the brainstem pyramidal tract in the cat, those cells with slowly conducting axons possess profuse distal apical tufts in layer I while fast pyramidal tract neurons have sparse distal apical dendrites (Deschenes et al., 1979). Miller et al. (1990) and Tseng and Prince (1993) have shown in the rat that the pyramidal tract neurons with extensive layer I dendrites includc intrinsically bursting neurons. Furthermore, two subsets of layer $V$ pyramidal cells in rat visual cortex have been distinguished: neurons with no layer I dendrites project to contralateral cortex, while the neurons with profuse layer I dendrites project subcortically to the superior colliculus (Hubener et al., 1990; see also Hallman et al., 1988). To the extent that the backward corticocortical projections exert their influence through their dense terminations in layer $I$, the forward and backward cortical pathways appear to engage separate populations of cortical cells, which in turn project to separate targets.

\section{References}

Adinolfi AM (1972) Morphogenesis of synaptic junctions in layers I and II of the somatic sensory cortex. Exp Neurol 34:372-382.

Agmon A, Connors BW (1991) Thalamocortical responses of mouse somatosensory (barrel) cortex in vitro. Neuroscience 41:365-379.

Agmon A, Connors BW (1992) Correlation between intrinsic firing patterns and thalamocortical synaptic responses of neurons in mouse barrel cortex. J Neurosci 12:319-329.

Amitai Y, Friedman A, Connors BW, Gutnick MJ (1993) Regenerative electrical activity in apical dendrites of pyramidal cells in neocortex. Cereb Cortex 3:26-38.

Anderson JC, Martin KAC, Picanco-Diniz CW (1992) The neurons of layer 1 in cat visual cortex. Proc R Soc Lond [Biol] 248:27-33.

Bear MF, Carnes KM, Ebner FE (1985) An investigation of cholinergic circuitry in cat striate cortex using acetylcholinesterase histochemistry. J Comp Neurol 234:411-430.

Beaulieu C, Colonnier M (1985) A laminar analysis of the number of round-asymmetrical and flat-symmetrical synapses on spines, dendritic trunks, and cell bodies in area 17 of the cat. $J$ Comp Neurol 231:180-189.

Bullier J, McCourt ME, Henry GH (1988) Physiological studies on the fecdback connection to the striate cortex from cortical areas 18 and 19 of the cat. Exp Brain Res 70:90-98.

Cauller LJ, Connors BW (1989) Origin and function of horizontal layer I afferents to rat SI neocortex. Soc Neurosci Abstr 15:281.

Cauller LJ, Connors BW (1990) Horizontal layer I inputs to primary somatosensory (barrelfield) neocortex of rat. Soc Neurosci Abstr 16: 242

Cauller LJ, Connors BW (1992) Functions of very distal dendrites: experimental and computational studies of layer I synapses on neocortical pyramidal cells. In: Single neuron computation (McKenna T, Davis J, Zornetzer SF, eds), pp 199-229. San Diego: Academic.

Cauller LJ, Kulics AT (1988) A comparison of awake and sleeping cortical states by analysis of the somatosensory-evoked potential in postcentral area 1 of rhesus monkey. Exp Brain Res 72:584-592.

Cauller LJ, Kulics AT (1991) The neural basis of the behaviorally relevant N1 component of the somatosensory-evoked potential in SI cortex of awake monkeys: evidence that backward cortical projections signal conscious touch sensation. Exp Brain Res 84:607-619.

Cauller LJ, Wehr M, Bulthoff I, Connors BW (1991) Simulations of dendritic integration in reconstructed pyramidal and nonpyramidal neurons of neocortex. Soc Neurosci Abstr 17:311.

Chagnac-Amitai Y, Luhmann HJ, Prince DA (1990) Burst generating and regular spiking layer 5 pyramidal neurons of rat neocortex have different morphological features. J Comp Neurol 296:598-613.

Connors BW, Gutnick MJ (1990) Intrinsic firing patterns of diverse neocortical neurons. Trends Neurosci 13:99-104.

Connors BW, Gutnick MJ, Prince DA (1982) Electrophysiological properties of neocortical neurons in vitro. J Neurophysiol 48:13021320.

Connors BW, Malenka RC, Silva LR (1988) Two inhibitory postsynaptic potentials, and $\mathrm{GABA}_{A}$ and $\mathrm{GABA}_{B}$ receptor-mediated responses in neocortex of rat and cat. J Physiol (Lond) 406:443-468.

Damasio AR (1989) The brain binds entities and events by multiregional activation from convergence zones. Neural Comput 1:123 132.

DeFelipe J, Jones EG (1988) Cajal on the cerebral cortex. New York: Oxford UP.

DeLima AD, Singer W (1986) Cholinergic innervation of the cat striate cortex: a choline acetyltransferase immunocytochemical analysis. J Comp Neurol 250:324-338.

Deschenes M, LaBelle A, Landry P (1979) Morphological characterizations of slow and fast pyramidal tract cells in the cat. Brain Res 178:251-274.

Eckhorn R, Reitboeck HJ, Arndt M, Dicke P (1990) Feature linking via synchronization among distributed assemblies: simulations of results from cat visual cortex. Neural Comput 2:293-307.

Edelman GM (1978) Group selection and phasic reentrant signalling: a theory of higher brain function In: The mindful brain (Schmitt FO, ed), pp 51-100. Cambridge, MA: MIT Press.

Edelman GM (1989) The remembered present: a biological theory of consciousness. New York: Basic Books.

Emson PC, Lindvall P (1979) Distribution of putative neurotransmitters in the cortex. Neuroscience 4:1-30.

Fabri, M, Burton H (1991) Ipsilateral cortical connections of primary somatic sensory cortex in rats. J Comp Neurol 311:405-424.

Felleman DJ, Van Essen DC (1991) Distributed hierarchical processing in the primate cerebral cortex. Cereb Cortex 1:1-47.

Gabbott PLA, Somogyi P (1986) Quantitative distribution of GABAimmunoreactive neurons in the visual cortex (area 17) of the cat. Exp Brain Res 61:323-331.

Hallman LE, Schofield BR, Lin C-S (1988) Dendritic morphology and axon collaterals of corticotectal, corticopontine, and callosal neurons in layer $\mathrm{V}$ of primary visual cortex of the hooded rat. J Comp Neurol 272:149-160.

Herkenham M (1986) New perspectives on the organization and evolution of nonspecific thalamocortical projections In: Cerebral cortex, Vol 5 (Jones EG, Peters A, eds), pp 403-445. New York: Plenum.

Hines M (1989) A program for simulation of nerve equations with branching geometries. Int J Biomed Comput 24:55-68.

Hubener M, Schwarz C, Bolz J (1990) Morphological types of projections neurons in layer 5 of cat visual cortex. J Comp Neurol 301: 655-674.

Huguenard JR, Hamill OP, Prince DA (1989) Sodium channels in dendrites of rat.cortical pyramidal neurons. Proc Natl Acad Sci USA 86:2473-2477.

Hyvarinen J (1982) The parietal cortex of monkey and man. New York: Springer.

Jones EG (1981) Anatomy of cerebral cortex: columnar inpul-output organization. In: The organization of the cerebral cortex (Schmitt FO, 
Worden FG, Adelman G, Dennis SG, eds), pp 199-235. Cambridge, MA: MIT Press.

Jones EG, Powell TPS (1970) electron microscopy of the somatic sensory cortex of the cat II the fine structure of layer I-II. Philos Trans R Soc Lond [Biol] 257:13-21.

Killackey HP, Ebner FF (1972) Two different types of thalamocortical projections to a single cortical area in mammals. Brain Behav Evol $6: 141-169$.

Kim HG, Connors BW (1993) Apical dendrites of the neocortex: correlation between sodium- and calcium-dependent spiking and pyramidal cell morphology. $J$ Neurosci, in press.

Koralek KA, Olavarria J, Killackey HP (1990) Areal and laminar organization of corticocortical projections in the rat somatosensory cortex. J Comp Neurol 299:133-150.

Larkman A, Mason A (1990) Correlations between morphology and electrophysiology of pyramidal neurons in slices of rat visual cortex. I. Establishment of cell classes. J Neurosci 10:1407-1414.

Luhmann H, Prince DA (1990) Transient expression of polysynaptic NMDA receptor-mediated activity during neocortical development. Neurosci Lett 111:109-115.

Lysakowski A, Wainer BH, Ryc DB, Bruce G, Hersh LB (1986) Cholinergic innervation displays strikingly different laminar preferences in several cortical areas. Neurosci Lett 64:102-108.

Martin KAC (1984) Neuronal circuits in cat striate cortex. In: Cerebral cortex, Vol 2 (Jones EG, Peters A, eds), pp 241-284. New York: Plenum.

Mesulam M-M (1978) Tetramethyl benzidine for horseradish peroxidase neurohistochemistry: a non-carcinogenic blue reaction-product with superior sensitivity for visualizing neural afferents and efferents. J Histochem Cytochem 26:106-117.

Mesulam M-M (1990) Large-scale neurocognitive networks and distributed processing for attention, language and memory. Ann Neurol 28:597-613.

Mignard M, Malpeli JG (1991) Paths of information flow through the visual cortex. Science 251:1249-1251.

Miller MW, Chiaia NL, Rhodes RW (1990) Intracellular recording and injection of corticospinal neurons in rat somatosensory cortex: effect of prenatal exposure to ethanol. J Comp Neurol 296:1-15.

Nakajima S, Komatsu Y, Toyama K (1988) Synaptic action of layer I fibers on cells in cat striate cortex. Brain Res 457:176-180.

Nicholson C (1979) Generation and analysis of extracellular field potentials. In: Society for Neuroscience short course: electrophysiological techniques, pp 93-148. Bethesda, MD: Society for Neuroscience.

Nitzan R, Segev I, Yarom Y (1990) Voltage behavior along the irregular dendritic structure of morphologically and physiologically characterized vagal motoneurons in the guinea pig. $\mathbf{J}$ Neurophysiol 63:333-346.

Olucha F, Martinez-Garcia F, Lopez-Garcia C (1985) A new stabilizing agent for the tetramethyl benzidine (TMB) reaction product in the histochemical detection of horseradish peroxidase (HRP). J Neurosci Methods 13:131-138.

Pandya DN, Yeterian EH (1985) Architecture and connections of cortical association areas. In: Cerebral cortex, Vol 4 (Peters A, Jones EG, eds), pp 3-61. New York: Plenum.
Penny GR, Itoh K, Diamond IT (1982) Cells of different sizes in the ventral nuclei project to different layers of the somatic cortex in the cat. Brain Res 242:55-65.

Pockberger H (1991) Electrophysiological and morphological properties of rat motor cortex neurons in vivo. Brain Res 539:181-190.

Rausell E, Avendano C (1985) Thalamocortical neurons projecting to superficial and to decp layers in parictal, frontal and prefrontal regions of the cat. Brain Res 347:159-165.

Rockland KS, Pandya DN (1979) Laminar origins and terminations of cortical connections of the occipital lobe in the rhesus monkey. Brain Res 179:3-20.

Rockland KS, Virga A (1989) terminal arbors of individual "feedback" axons projecting from $\mathrm{V} 2$ to $\mathrm{V} 1$ in the macaque monkey: a study using immunohistochemistry of anterogradely transported Phaseolus vulgaris-leucoagglutinin. J Comp Neurol 285:54-72.

Rolls ET (1989) Functions of neuronal networks in the hippocampus and neocortex in memory. In: Neural models of plasticity (Byrne JH, Berry WO, eds), pp 240-265. San Diego: Academic.

Sah P, Hestrin S, Nicoll RA (1989) Tonic activation of NMDA receptors by ambient glutamate enhances excitability of neurons. Scicncc 246:815-818.

Sandell JH, Schiller PH (1982) Effect of cooling area 18 on striate cortex cells in squirrel monkey. J Neurophysiol 48:38-48.

Sporns O, Gally JA, Reeke GN, Edelman GM (1989) Reentrant signaling among simulated neuronal groups leads to coherency in their oscillatory activity. Proc Natl Acad Sci USA 86:7265-7269.

Squire LR, Zola-Morgan S (1991) The medial temporal lobe memory system. Science 253:1380-1386.

Staley KJ, Otis TS, Mody I (1992) Membrane properties of dentate granule cells: comparison of sharp microelectrodes and whole-cell recordings. J Neurophysiol 67:1346-1358.

Stratford K, Mason A, Larkman A, Major G, Jack J (1989) The modelling of pyramidal neurons in visual cortex. In: The computing neuron (Durbin R, Miall C, Mitchison G, eds), pp 296-321. Wokingham, UK: Addison-Wesley.

Sutor B, Hablitz JJ (1989) EPSPs in rat neocortical neurons in vitro. II. Involvement of $N$-methyl-D-aspartate receptors in the generations of EPSPs. J Neurophysiol 61:621-634.

Tseng G-F, Prince DA (1993) Heterogeneity of rat corticospinal neurons. J Comp Neurol, in press.

Vaughan DW, Peters A (1973) A three dimensional study of layer I of the rat parietal cortex. J Comp Neurol 149:355-370.

Vogt BA (1991) The role of layer I in cortical function. In: Cerebral cortex, Vol 9 (Peters A, ed), pp 49-80. New York: Plenum.

Vogt BA, Gorman ALF (1982) Responses of cortical neurons to stimulation of corpus callosum in vitro. J Neurophysiol 48:1257-1273.

Winer JA, Larue DT (1989) Populations of GABAergic neurons and axons in layer I of rat auditory cortex. Neuroscience 33:499-515.

Wong-Riley M (1978) Reciprocal connections between striate and prestriate cortex in squirrel monkey as demonstrated by combined peroxidase histochemistry and autoradiography. Brain Res 147:159_ 164.

Zeki S, Shipp S (1988) The functional logic of cortical connections. Nature 353:311-317. 